\title{
Time Course of Histomorphologic Features during Chronic Burn Wound Healing
}

\author{
Yasser S. El-Sayed \\ Department of Veterinary Forensic Medicine and Toxicology, Faculty of Veterinary Medicine, Damanhour \\ University, Damanhour, Egypt \\ Email: yasser_tf@yahoo.com, elsayed-ys@vetmed.dmu.edu.eg
}

Received 30 October 2015; accepted 14 December 2015; published 17 December 2015

Copyright (C) 2016 by author and Scientific Research Publishing Inc.

This work is licensed under the Creative Commons Attribution International License (CC BY).

http://creativecommons.org/licenses/by/4.0/

c) (i) Open Access

\begin{abstract}
In forensic pathology, it is always indispensable to determine burn wound vitality or age to accurately assess the relationship between death and any burn wounds. Subsequently, the determination of wound age is a definitive and still cutting-edge subject in forensic pathology. Therefore, deep second-degree burn injuries were induced in a group of mice. At 7, 12, 17, 21 and 28 days post-burn, burn wound specimens were histomorphologically differentiated and compared with normal intact skin using H\&E stain. The study revealed that the burn wound during healing process was usually incorporated of infiltration of inflammatory cells, granulation tissue formation and epithelialization within 7 - 12 days post-burn. Then, the surface of burn wound was partially ulcerated in association with epidermal necrosis, dermal disorganization and degeneration of the sebaceous gland 17 - 21 days post-burn. Finally, the regenerated skin retained the structure of normal skin at 28th day post-burn. Our study demonstrated that the histopathological changes of burn wounds involved deep dermis, and the pathological changes occurred at distinctive time phases were almost different in comparing to regular intact skin. Such age estimation of burn wounds is important when a cadaver or a burnt body has many burns of diverse times, especially in criminal cases.
\end{abstract}

\section{Keywords}

Forensic Medicine, Skin Pathology, Burn, Age of Wound

\section{Introduction}

In forensic practice, it is doubtless that wound examination is one of the consequential and necessary areas for forensic pathologists. During the process of wound investigation, to assess the causalcorrelation between death and any wounds, forensic pathologists are always required to differentiate antemortem wounds from postmortem 
damage or to estimate wound age. It is likewise important to figure out whether a wound has vital reaction, and if so, how long before the wound has been sustained [1]. In other words, the determination of wound vitality or wound age has to be always performed. The short and simplified overview of wound healing can be adopted to determine wound vitality or wound age in forensic medicine. Forensic pathologists can determine how long a victim has been exposed by the age estimation of burns. However, aging of burn injuries by visual observation is sometimes difficult and uncertain [2] [3].

Histopathological examination remains to be a more reliable technique, which provides an experimental basis for the distinction between ante- and post-mortem wounds, and determining the age of wounds [4]. Histopathological alterations characterizing the distinctive phases of wound healing can be applied to estimate the approximate age of wounds, especially of those inflicted within the early hours of wounding [5]. Therefore, aging of burn wounds is one of the most important medico-legal problems based on the observation of a normal course of the burn healing process. During the healing process, several morphologically distinguishable phenomena occur, and their microscopical detection determines the wound age whereas the absence of these parameters provides fewer reliable results and often cannot be interpreted under forensic aspects [2] [4]. In this way, the following study aimed to recognizethe pathomorphological changes in healing of chronic deep seconddegree burns that may be more constant in their time sequence, thus enabling an assessment of the burn wound vitality and age.

\section{Materials and Methods}

\subsection{Animals}

Thirty-six male Swiss albino mice of 10 - 12 weeks-old, 25 - 30 g body weight, were obtained from the Laboratory Animal House, High Institute of Public Health, Alexandria University, Alexandria, Egypt. The animals were randomized into control (unburnt) and burnt groups at one time. They were kept in cages numbered 1 to 6 , and housed in a temperature-controlled room $\left(27^{\circ} \mathrm{C}-30^{\circ} \mathrm{C}\right)$. Twelve-hour light-dark cycle was maintained with lights on at 6 am and off at $6 \mathrm{pm}$. In order to minimize all undesired stressors, such as handling, habitat etc., the animals were acclimatized to the environment for at least one week in the animal house at the institutional department. The animals were allowed to recover, housed separately, and fed ad libitum until the wounds were harvested.

\subsection{Burn Injury Induction}

Under ether anesthesia, animals were shaved and clipped on the dorsal area between the last thoracic and first sacrum vertebrae. The clipped areas were swabbed with betadine and ethanol $70 \%$. Then, deep second-degree burn injuries were induced on the skin of the treated group by pressing a red-hot steel instrument $112^{\circ} \mathrm{C}$ witha $(1.5 \times 1.5 \mathrm{~mm})$ cross sectional area for 2-second exposure time. The animal experiments were performed in accordance with the institutional and national guidelines for the care and use of laboratory animals.

\subsection{Histopathology}

At zero day in control goup (unburnt group), and at 7th, 12th, 17th, 21st and 28th days after burning in burnt group, 6 animals were sacrificed by exsanguination under ether anesthesia. Then, burn wound samples were immediatly harvasted using a 6-mm punch biopsy. From each animal, one wound was immediately fixed in neutral buffered formalin $10 \%$ for a period of at least 24 hours. The fixed tissue specimens were then dehydrated in ethanol (50\% - 100\%) and embedded in paraffin, cut into sections of $4-5 \mu \mathrm{m}$ thickness parallel to the longitudinal axis of the body. The sections were stained using routine hematoxylin-eosin stain [6]. The phenotype of wound healing was assessed by light microscopy. From each sample, at least three sections through the center of the wound were examined for re-epithelialization, granulationt issue formation, and inflammatory response. The burnwound edge was used as the point where there was a clear margin in which subcutaneous fat tissue, mature collagen or hair follicles were absent.

\section{Results}

Under the light microscope, the normal intact skin reveals epidermis lined by stratified squamous epithelium with all layers; granular, basal, spinous and cornfied layers. The dermis is intact containing blood vessels and 
few lymphocytes (Figure 1). In relation to intact skin, all burn wounds were noted to involve deep dermis and the pathological changes of burn wounds at distinct time phases were almost different. On 7th day post-burn, the dermal and epidermal layers are disorganized with granulation tissue formation around sebaceous glands (Figure 2(a)). The superficial necrotic tissues in the dermis were liquefied, discharged and thinned. The epidermis became necrotic due to collagen degeneration and granulation tissue formation. In addition, neoformative small-sized blood vessels with presence of fibroblast and infiltration of many inflammatory cells, including neutrophil, lymphocytes, polymorphs and histocytes were visible in wounds (Figure 2(b)). On 12th day postburn, the wound character is still clearly similar to 7th day post-burn. However, the burn showing fibrinoid necrosis with degeneration of collagen and sebaceous gland (Figure 3(a) and Figure 3(b)).

On 17th day post-burn, the burn wound is showing partial surface ulceration with epidermal necrosis and loses. It was infiltrated with fibroblast, histocytes, lymphocytes and polymorphs (Figure 4(a)). The dermis shows disorganization with collagen and degeneration of the sebaceous gland (Figure 4(b)). On 21st day postburn, the burn wound is showing partial surface ulceration with dermal granulation tissue formation (Figure 5). On 28th day post-burn, the epidermis becomes thin with dermal disorganization, fibrous tissue formation and degeneration of the hair follicle (Figure 6(a) and Figure 6(b)).

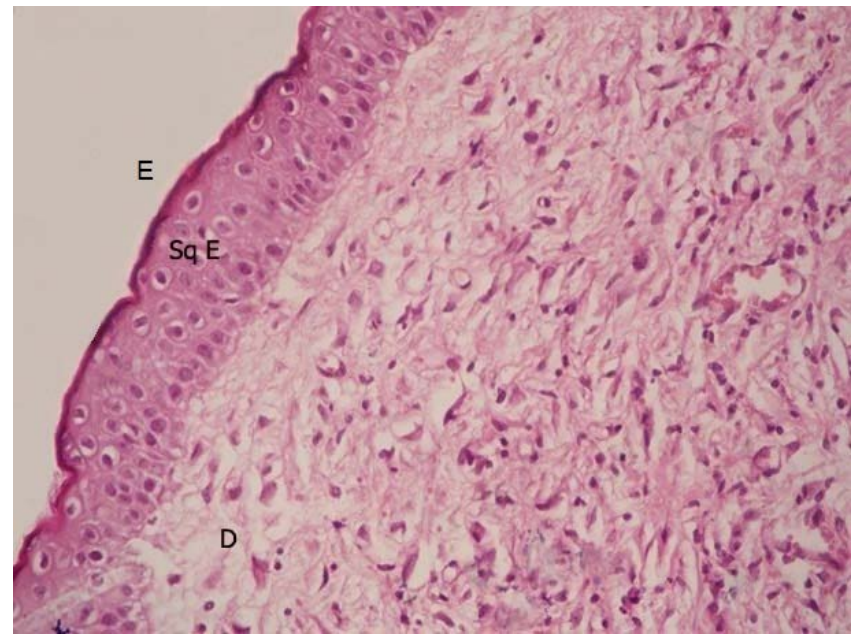

Figure 1. Photomicrograph of skin of control animal (unburnt mice) stained with $\mathrm{H}$ \& $\mathrm{E}$ showing epidermis (E) lined by stratified squamous epithelium (Sq E) showing all layers (granular, basal, spinous and cornfied layers). The dermis (D) is intact containing blood vessels and few lymphocytes $(\times 400)$.
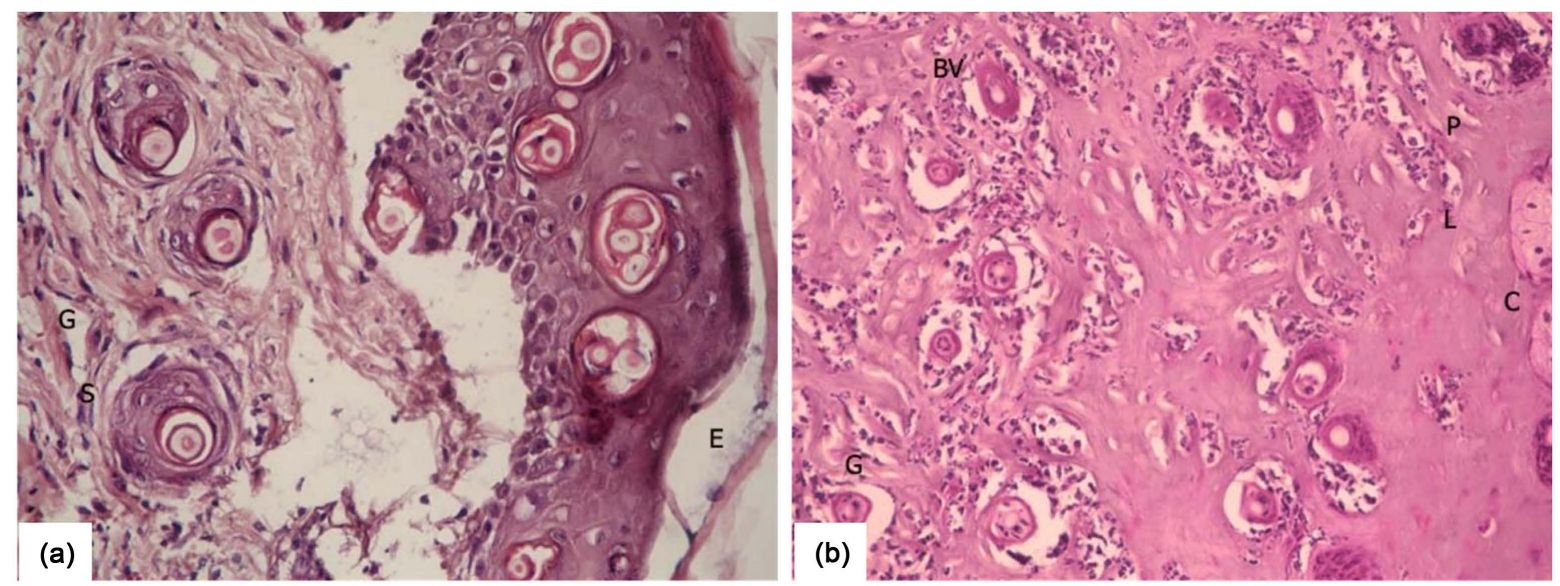

Figure 2. Photomicrograph of skin of burnt mice 7days post-burn stained with $\mathrm{H} \& \mathrm{E}$ showing epidermal and dermal disorganization (E) with a granulation tissue $(\mathrm{G})$ formation around sebaceous glands $(\mathrm{S})((\mathrm{a}), \times 400)$. The burn reveals collagen degeneration (C) and granulation tissue formation (G), formed of small-sized blood vessels (BV) with presence of fibroblast, lymphocytes (L), polymorphs (P) and histocytes ((b), ×400). 

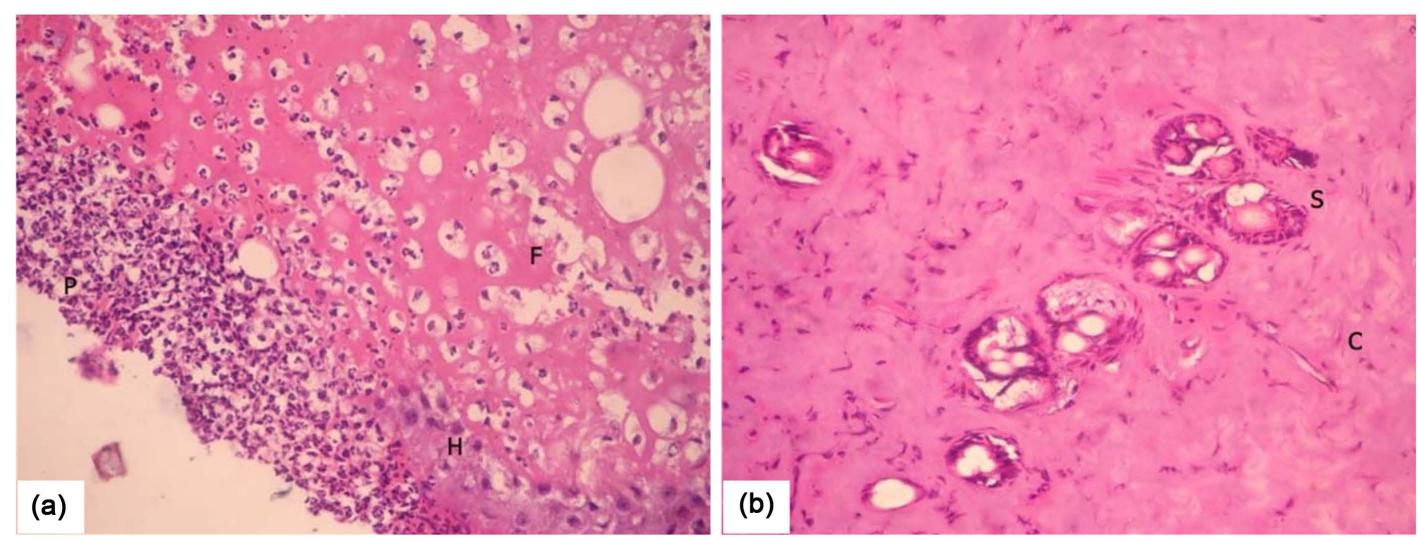

Figure 3. Photomicrograph of skin of burnt mice 12 days post-burn stained with H \& E showing fibrinoid necrosis (F) and granulation tissue formation, formed of small-sized blood vessels with presence of fibroblast, polymorphs $(\mathrm{P})$, histocytes $(\mathrm{H})$ and lymphocytes ((a), ×400). The burn reveals collagen (C) and sebaceous gland degeneration(S) ((b), $\times 400)$.
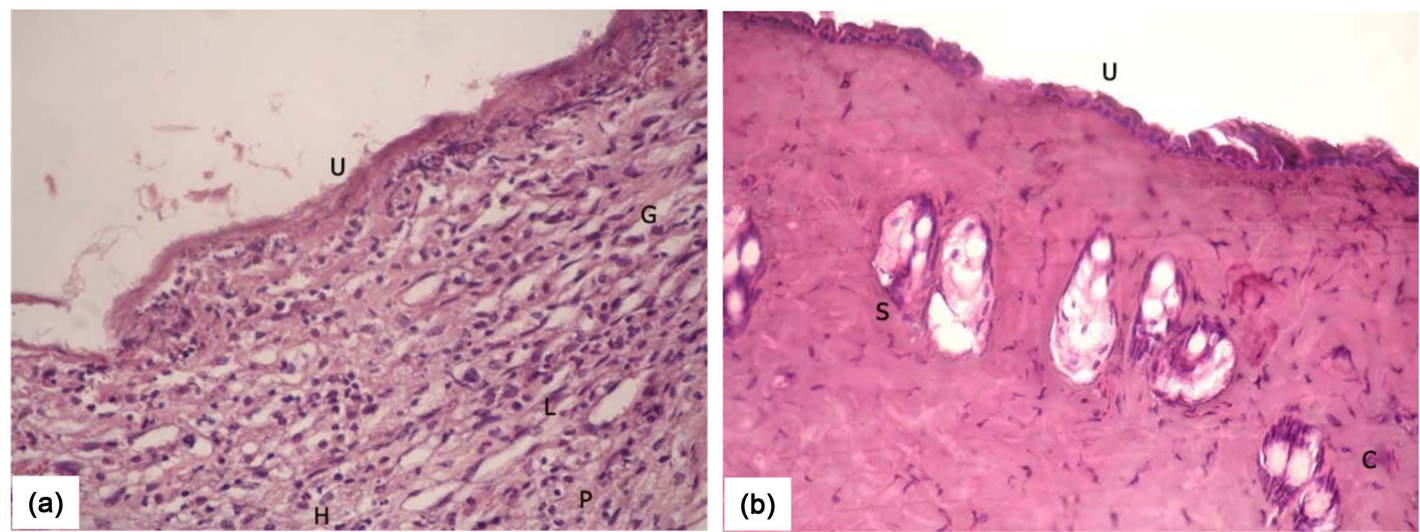

Figure 4. Photomicrograph of skin of burnt mice 17 days post-burn stained with $\mathrm{H}$ \& E showing surface ulceration (U) with granulation tissue formation (G) formed of fibroblast, histocytes (H), lymphocytes (L) and polymorphs (P) ((a), ×400). The burn reveals partial surface ulceration (U) with epidermal necrosis and loses. The dermis shows disorganization with collagen (C) and sebaceous gland (S) degeneration ((b), ×400).

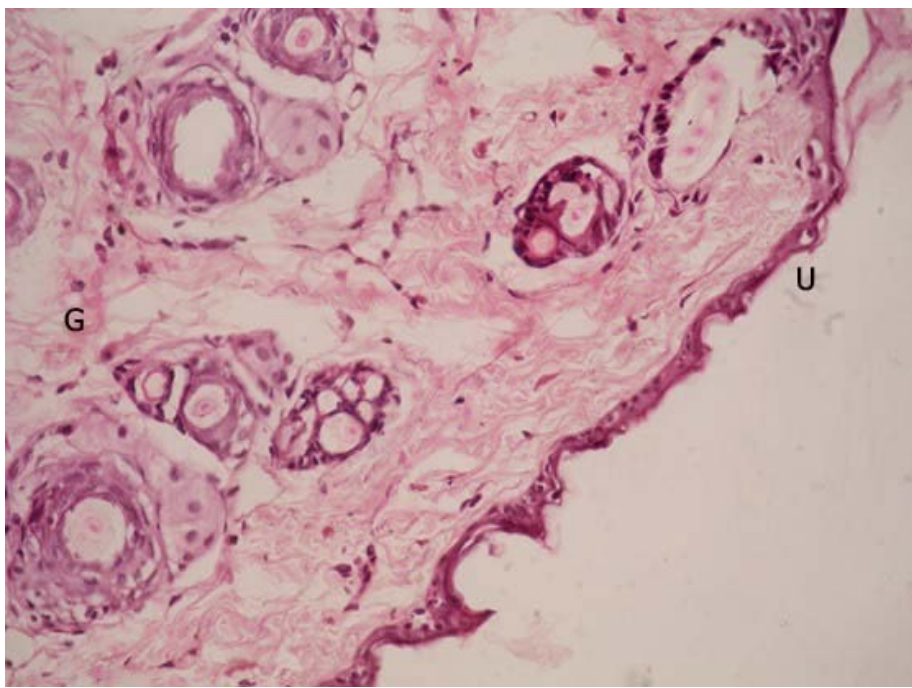

Figure 5. Photomicrograph of skin of burnt mice 21 days post-burn stained with $\mathrm{H} \& \mathrm{E}$ showing partial surface ulceration (U). Dermis shows granulation tissue formation $(G)(\times 400)$. 

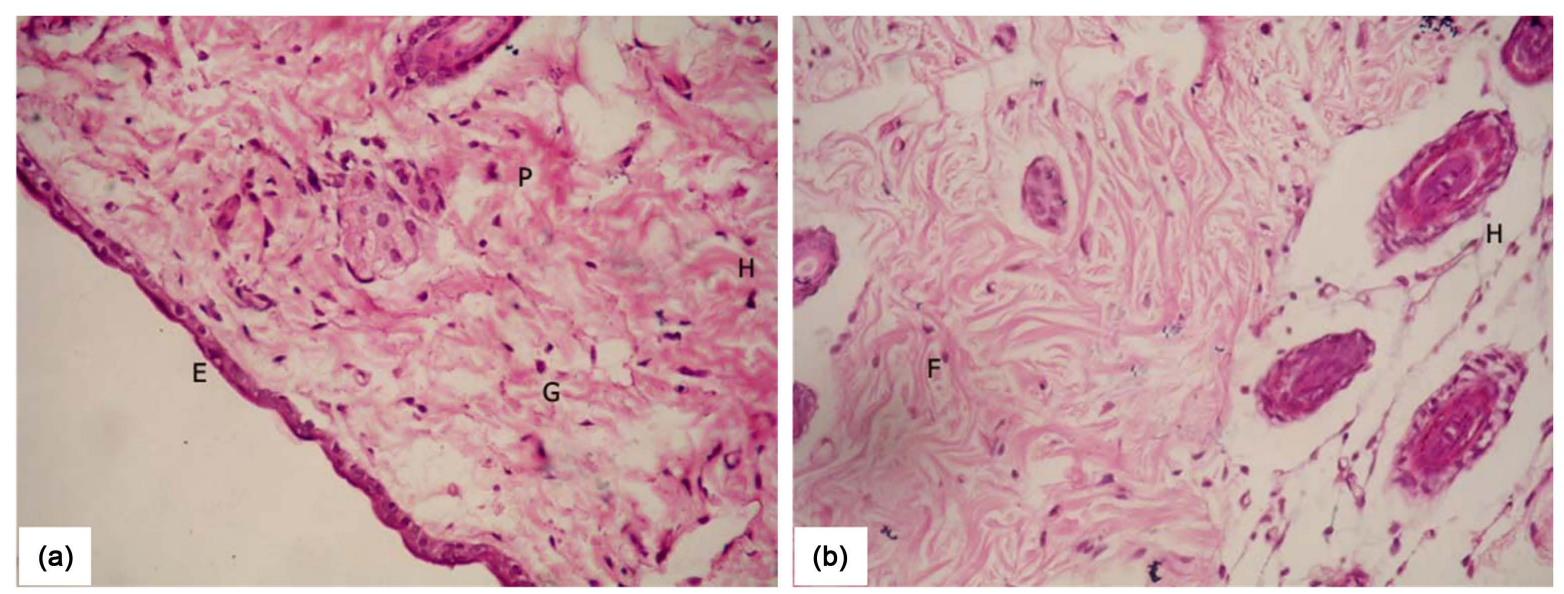

Figure 6. Photomicrograph of skin of burnt mice 28 days post-burn stained with $\mathrm{H} \& \mathrm{E}$ showing epidermal (E) thinning with dermal disorganization and fibrous tissue formation $((\mathrm{a}), \times 400)$. The burn reveals degeneration of the hair follicle $(\mathrm{H})$ with fibrous (F) tissue formation (scar) ((b), ×400). (G), Granulation tissue formation; (P), Polymorphs.

\section{Discussion}

From the viewpoint of forensic pathology as well, these pathomorphological changes show the possibility of available timing for wound age determination. Normal wound healing is usually divided into three stages: 1) inflammation, 2) epithelialization and granulation tissue formation, and 3) matrix formation and remodeling [7] [8]. Chronic wounds are characterized by a prolonged inflammatory response with disturbed cellular constituents [9] [10]. Histologic examination of the burn edge, to include both the burned area and adjacent grossly unburned skin, may reveal vital reaction microscopically, consisting of acute inflammation, edema, and necrosis [11] [12]. These findings are present only in antemortem burns, thereby assisting in the delineation of whether the decedent was alive when the burns occurred. Additionally, a section of the skin in burns may document necrosis, vertical streaming of the epidermal nuclei, and homogenation of the dermal collagen. Our study demonstrated that the histopathological changes of burn wounds involved deep dermis and the pathological changes of burns at distinctive time phases were almost different in comparing to normal intact skin. On days 7 12 post-burn, the pathomorphological change was characterized by the disorganization with granulation tissue formation and necrosis of occurred in the burned epidermis and superficial dermis, revealing inflammatory response, with signs of "leukocyte infiltration". The necrotic tissue began to liquefy and discharge increasingly as the disease course progressed [12]. Such changes increased around days 12 - 17 post-burn when dermal degeneration of sebaceous gland, fibroblasts, histocytes, as well as other repaired cells, showed signs of regeneration.

On 7th day post-burn, wound liquefaction became noticeable and peaked. After that, liquefaction reduced with less necrotic tissue. The inflammatory response, however, remained correlated with the liquefaction of necrotic tissue. Repair by regeneration was noted on 12th day post-burn and manifested mainly by fibroblasts, histocytes, as well as other repaired cells. This stimulated the proliferation of peripheral fibroblasts and endothelia, and further formed granulation tissues, leading to final healing by epithelization [8] [12]. Later, the surface of burn wound is partially ulcerated with epidermal necrosis, dermal disorganization and degeneration of the sebaceous gland 17 - 21 days post-burn. After experiencing further differentiation and neoformation, the regenerated skin finally attained the structure of normal skin at 28th day post-burn. In this way, the study demonstrates that recognizing the histopathological changes in normal healing process of burns is more constant in their time sequence, thus enabling an assessment of the burn wound vitality and age. Such age estimation of burn wounds is vital when a cadaver or a burnt body has many burns of different ages, particularly in criminal cases.

\section{References}

[1] Kondo, T. (2007) Timing of Skin Wounds. Legal Medicine (Tokyo), 9, 109-114. http://dx.doi.org/10.1016/j.legalmed.2006.11.009

[2] Cecchi, R. (2010) Estimating Wound Age: Looking into the Future. International Journal of Legal Medicine, 124, 523- 
536. http://dx.doi.org/10.1007/s00414-010-0505-x

[3] Gerling, I., Meissner, C., Reiter, A. and Oehmichen, M. (2001) Death from Thermal Effects and Burns. Forensic Science International, 115, 33-41. http://dx.doi.org/10.1016/S0379-0738(00)00302-9

[4] Raekallio, J. (1975) Histological Estimation of the Age of Injuries. In: Perper, J.A. and Wechts, C.H., Eds., Microscopic Diagnosis in Forensic Pathology, Thomas, Springfield, 3-16.

[5] Betz, P. (1994) Histological and Enzyme Histochemical Parameters for the Age Estimation of Human Skin Wounds. International Journal of Legal Medicine, 107, 60-68. http://dx.doi.org/10.1007/BF01225491

[6] Suvarna, K.S., Layton, C. and Bancroft, J.D. (2013) Bancroft's Theory and Practice of Histological Techniques. Churchill Living Stone, Edinburg, London, Melbourne.

[7] Borena, B.M., Martens, A., Broeckx, S.Y., Meyer, E., Chiers, K., Duchateau, L. and Spaas, J.H. (2015) Regenerative Skin Wound Healing in Mammals: State-of-the-Art on Growth Factor and Stem Cell Based Treatments. Cellular Physiology and Biochemistry, 36, 1-23. http://dx.doi.org/10.1159/000374049

[8] Regan, M.C. and Barbul, A. (2011) Cellular Biology of Wound Healing. http://www.neuro.ki.se/neuro/KK2/Jimmy_GoogleCACHE1.html

[9] Tomic-Canic, M., Agren, M.S. and Alvares, O.M. (2004) Epidermal Repair and Chronic Wounds. In: Rovie, D.T. and Maibach, H., Eds., The Epidermis in Wound Healing, CRS Press, New York, 26.

[10] Zhao, G., Usui, M.L., Underwood, R.A., Singh, P.K., James, G.A., Stewart, P.S., Fleckman, P. and Olerud, J.E. (2012) Time Course Study of Delayed Wound Healing in a Biofilm-Challenged Diabetic Mouse Model. Wound Repair and Regeneration, 20, 342-352. http://dx.doi.org/10.1111/j.1524-475X.2012.00793.x

[11] Rao, D. (2015) Thermal Injuries. http://www.forensicpathologyonline.com/

[12] Xu, R.X. (2004) Physiological Healing Procedure and Histological Observation on Deep Second-Degree Burns Treated with BRT with MEBT/MEBO. In: Sun, X. and Weeks, B.S., Eds., Burns Regenerative Medicine and Therapy, S. Karger, Basel, 106-111. 